\title{
Between fire and flood. Drug-induced QT prolongation causes torsades de pointes and electrical storm
}

\author{
Katarzyna Styczkiewicz' ${ }^{1}$, Piotr Kukla², Anna Czerkies-Bieleń ${ }^{1}$, Marek Styczkiewicz ${ }^{1}$
}

\author{
1Department of Cardiology, Brzozów Specialist Hospital, Subcarpathian Oncological \\ Center, Brzozow, Poland \\ 2Department of Cardiology and Internal Medicine, Specialist Hospital, Gorlice, Poland
}

Submitted: 12 May 2019

Accepted: 12 June 2019

Arch Med Sci Civil Dis 2019; 4: e72-e74

DOI: https://doi.org/10.5114/amscd.2019.86922

Copyright $\odot 2019$ Termedia \& Banach

Electrocardiography (ECG) is recommended for all patients undergoing anti-cancer therapy before and during treatment [1]. However, the problem of drug-induced QT interval prolongation is often underestimated, sometimes leading to severe consequences including life-threatening torsades de pointes (TdP). We describe here a case of a 50-year-old woman with no previous cardiac history and no chronic diseases requiring drug therapy, hospitalized at the Hematology Unit with a diagnosis of acute lymphoblastic leukemia. The patient received 2 rounds of initial chemotherapy - doxorubicin, vincristine and prednisolone. Unfortunately, further hospitalisation was complicated by severe atypical pneumonia and fungal infection. The patient's condition was critical, requiring a week stay at the Intensive Care Unit. Chemotherapy was suspended and antibiotics (clarithromycin) and antifungal treatment (voriconazole) were introduced. After 2 weeks of therapy, the patient had a sudden cardiac arrest but was successfully reanimated. Her laboratory tests showed potassium $3.4 \mathrm{mmol} / \mathrm{l}$ (below normal), hemoglobin $8.0 \mathrm{~g} / \mathrm{dl}$ (below normal), C-reactive protein $90 \mathrm{mg} / \mathrm{l}$ (above normal), D-dimer $12 \mu \mathrm{g} /$ $\mathrm{ml}$ (above normal), and troponin $\mathrm{T} 0.058 \mathrm{ng} / \mathrm{ml}$ (normal). As frequent ventricular extrasystoles were observed, an amiodarone bolus of $300 \mathrm{mg}$ was administered, and a cardiologist was consulted, who obtained an ECG. A sinus rhythm of $85 / \mathrm{min}$ with significant QT prolongation (QTC $580 \mathrm{~ms}$ ) was observed (Figure $1 \mathrm{~A}$ ), while in ECG performed at the patient's admission to the hospital, QTc was normal, $456 \mathrm{~ms}$. The patient was recommended to stop the QT-prolonging therapy and continue ECG monitoring. On echocardiography, the left ventricle ejection fraction was moderately decreased to $40 \%$. Due to the clinical suspicion of pulmonary embolism, suggested by active cancer treated by chemotherapy, inverted T waves in leads V4-V6 on ECG (Figure $1 \mathrm{~A}$ ) and an elevated D-dimer level, the patient underwent computed tomographic pulmonary angiography, which failed to detect any pulmonary embolisms. The patient's clarithromycin and voriconazole were stopped, and the electrolyte depletion was corrected. However, due to the observed ventricular arrhythmia, amiodarone infusion was continued during the night shift

The next morning, she experienced an electrical storm that recurred for several hours with multiple episodes of TdP (Figure 1 B) and cardiac arrests requiring defibrillation. The patient was transferred to the Cardiology Unit, amiodarone was discontinued, and she was treated with magnesium infusions and increasing $\beta$-blocker doses, with a final dose

\author{
Corresponding author: \\ Katarzyna Styczkiewicz MD, \\ $\mathrm{PhD}$ \\ Department \\ of Cardiology \\ Brzozów Specialist \\ Hospital \\ Subcarpathian \\ Oncological Center \\ 18 Bielawskiego St \\ 36-200 Brzozow, Poland \\ Phone: + 48134307940 \\ Fax: + 48134307940 \\ E-mail: krachwal@interia.pl
}


A

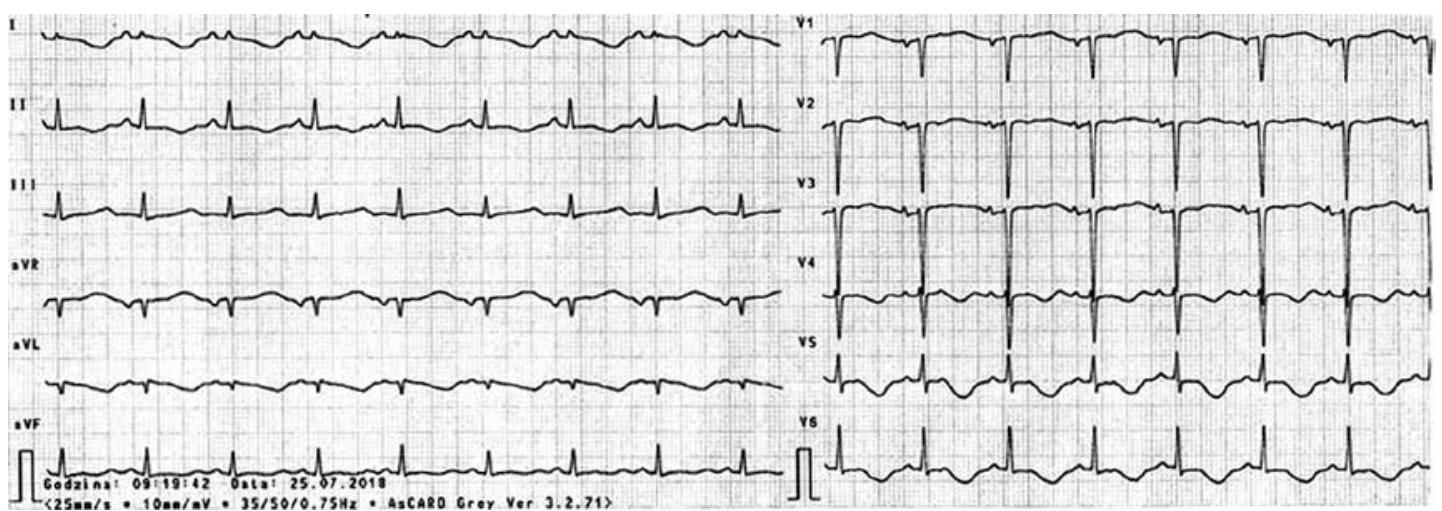

B



C

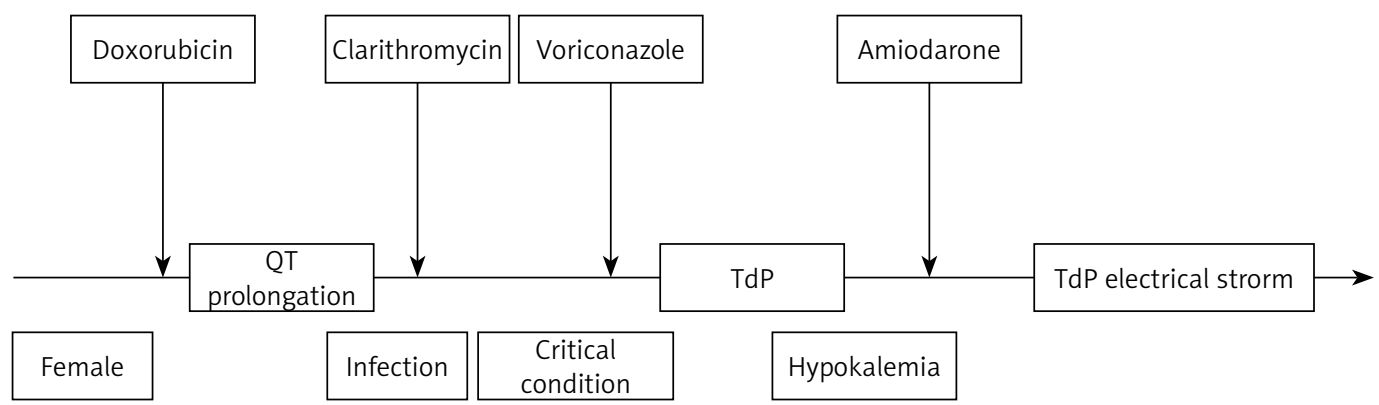

Figure 1. A - Electrocardiogram with prolonged QT (QTc $580 \mathrm{~ms}$ ) before the start of the electrical storm. B - Non-sustained ventricular tachycardia of torsades de pointes during Holter monitoring. C - Flowchart showing combination of possible factors contributing to the electrical storm in the patient

of $125 \mathrm{mg}$ of metoprolol. The number of TdP episodes significantly decreased after several hours, but the QT interval was still prolonged on ECG. After 2 days, the patient's condition improved, and free from ventricular arrhythmia, she was moved back to the Hematology Unit. A follow-up ECG was performed one month later, with a QTC of $450 \mathrm{~ms}$. The multiple possible factors contributing to drug-induced $\mathrm{QT}$ prolongation and $\mathrm{TdP}$ in this patient are shown in Figure $1 \mathrm{C}$.

We discussed this case to emphasize that although the number of patients who develop TdP with QT prolongation is small, multiple risk factors for QT prolongation may result in an exploding electrical storm [2, 3]. Much attention is currently paid to echocardiographic monitoring during anti-cancer therapy, particularly when it involves anthracyclines, but other cardiotoxic effects are ignored. Recent advances in cancer treatment and the introduction of new targeted therapies necessitate careful evaluation for QT changes especially in the context of other underlying exacerbating arrhythmia-inducing factors.

\section{Conflict of interest}

The authors declare no conflict of interest. 
References

1. Zamorano JL, Lancellotti P, Rodriguez Muñoz D, et al. 2016 ESC Position Paper on cancer treatments and cardiovascular toxicity developed under the auspices of the ESC Committee for Practice Guidelines. Eur Heart J 2016; 37: 2768-801.

2. Porta-Sánchez A, Gilbert C, Spears D, et al. Incidence, diagnosis, and management of qt prolongation induced by cancer therapies: a systematic review. J Am Heart Assoc 2017; 6: pii: e007724. doi: 10.1161/JAHA.117.007724.

3. Kishi S, Yoshida A, Yamauchi T, et al. Torsade de pointes associated with hypokalemia after anthracycline treatment in a patient with acute lymphocytic leukemia. Int J Hematol 2000; 71: 172-9. 